\title{
Lin-28 binds IGF-2 mRNA and participates in skeletal myogenesis by increasing translation efficiency
}

\author{
Anna Polesskaya, ${ }^{1,2,5}$ Sylvain Cuvellier, ${ }^{1,2}$ Irina Naguibneva, ${ }^{1,2}$ Arnaud Duquet, ${ }^{1,4}$ Eric G. Moss, ${ }^{3}$ \\ and Annick Harel-Bellan ${ }^{1,2}$ \\ ${ }^{1}$ Centre National de la Recherche Scientifique (CNRS) FRE 2944, Institut André Lwoff, Villejuif F-94801, France; ${ }^{2}$ Université \\ Paris-Sud, Villejuif F-94801, France; ${ }^{3}$ Department of Molecular Biology, University of Medicine and Dentistry of New Jersey, \\ Stratford, New Jersey 08084, USA
}

Lin-28 is a highly conserved, RNA-binding, microRNA-regulated protein that is involved in regulation of developmental timing in Caenorhabditis elegans. In mammals, Lin-28 is stage-specifically expressed in embryonic muscle, neurons, and epithelia, as well as in embryonic carcinoma cells, but is suppressed in most adult tissues, with the notable exception of skeletal and cardiac muscle. The specific function and mechanism of action of Lin-28 are not well understood. Here we used loss-of-function and gain-of-function assays in cultured myoblasts to show that expression of Lin-28 is essential for skeletal muscle differentiation in mice. In order to elucidate the specific function of Lin-28, we used a combination of biochemical and functional assays, which revealed that, in differentiating myoblasts, Lin-28 binds to the polysomes and increases the efficiency of protein synthesis. An important target of Lin-28 is IGF-2, a crucial growth and differentiation factor for muscle tissue. Interaction of Lin-28 with translation initiation complexes in skeletal myoblasts and in the embryonic carcinoma cell line P19 was confirmed by localization of Lin-28 to the stress granules, temporary structures that contain stalled mRNA-protein translation complexes. Our results unravel novel mechanisms of translational regulation in skeletal muscle and suggest that Lin-28 performs the role of "translational enhancer" in embryonic and adult cells and tissues.

[Keywords: Lin-28; RNA; skeletal muscle; translational regulation]

Supplemental material is available at http://www.genesdev.org.

Received October 18, 2006; revised version accepted March 7, 2007.

Lin-28 is a small RNA-binding protein that was originally described as an indispensable regulator of developmental timing in Caenorhabditis elegans (Moss et al. 1997). In nematodes, Lin-28 is expressed during early embryogenesis and is strongly down-regulated in adult life (Moss and Tang 2003). Repression of Lin-28 in C. elegans was shown to occur post-transcriptionally, and to be controlled by a microRNA (miRNA), lin-4, and by a protein, Lin-14 (Seggerson et al. 2002). In mammals, Lin-28 is ubiquitously expressed in embryonic stem (ES) cells and in early embryogenesis, but its expression becomes restricted to several tissues in late embryogenesis and in adult life (Yang and Moss 2003). Lin-28 is highly conserved throughout the species and presents a unique combination of RNA-binding motifs (a cold-shock domain, CSD, and two retroviral-type CCHC zinc finger motifs, ZFM). Conservation of Lin-28 in multiple species

${ }^{4}$ Present address: Department of Genetic Medicine and Development, University of Geneva Medical School, 1, rue Michel Servet, CH-1211, Geneva 4, Switzerland.

${ }^{5}$ Corresponding author.

E-MAIL apoles@vjf.cnrs.fr; FAX 33-1-49583307.

Article is online at http://www.genesdev.org/cgi/doi/10.1101/gad.415007. suggests an important physiological role for this small $(\sim 28 \mathrm{kDa})$, cytoplasmic, RNA-binding protein. However, no function has yet been attributed to Lin-28, and the existing knowledge about its expression and tissuespecificity has made it difficult to predict such a function.

In some mammalian differentiation models, such as retinoic acid (RA)-induced differentiation of P19 embryonic carcinoma (EC) cells, the control of Lin-28 expression was shown to depend on miR-125b, by a mechanism homologous to the regulation of Lin-28 by lin-4 in nematodes (Bagga et al. 2005; Wu and Belasco 2005). Interestingly, in other in vitro differentiation systems, such as TERA-2 EC cells, differentiation-related down-regulation of Lin-28 is not regulated by miR-125b, and is controlled at the transcriptional level (Lee et al. 2005). These results show that, in different tissues, Lin-28 can be regulated by completely different mechanisms, either miRNA-dependent or miRNA-independent. In any case, cell differentiation is associated with down-regulation of Lin-28 in most mammalian cell culture models, and Lin28 has been cited as a marker of "stemness" (Richards et al. 2004). 
Indeed, during mouse embryogenesis, expression of Lin-28 was shown to be high and widespread throughout tissues and embryonic layers until day 8.5-10.5. At this stage, however, it starts to show some tissue specificity; it is detected in epithelial tissues, in developing myocardium, and then in the myotome of developing somites around day 15.5 of embryogenesis (Yang and Moss 2003). The presence of Lin-28 in cardiac and skeletal muscle was reported to be continuous from this point on, and to persist in late embryogenesis and even in adult life. Therefore, in muscle tissue, Lin-28 appears to be associated with a differentiated state, in sharp contrast to results obtained in in vitro models of RA-induced differentiation of EC cells, and differentiation of ES cells (Sempere et al. 2004).

We have explored the function of Lin-28 in mammalian skeletal muscle. Our results show that in adult primary myoblasts (PMs), Lin-28 is strongly induced during differentiation. Conversely, miR-125b, the microRNA that controls Lin-28 expression in C. elegans, is downregulated in differentiating myoblasts, suggesting that the miR-125-Lin-28 regulation pathway is conserved in mammals. Gain- and loss-of-function assays demonstrated the importance of Lin-28 for differentiation: Specific repression of Lin-28 by RNA interference (RNAi) dramatically decreased the efficiency of muscle differentiation, and, conversely, overexpression of Lin-28 in a myoblast cell line (C2C12) had a stimulating effect on terminal differentiation. In regenerating skeletal muscle in vivo, Lin-28 is up-regulated during the differentiation and maturation of newly formed fibers. Mouse ES cells that have been fully committed to the myogenic lineage by stable expression of low levels of the muscle transcription factor MyoD express Lin-28 during differentiation, whereas in control ES cells, Lin-28 is down-regulated during formation of heterogeneous embryoid bodies (EB; 95\%-100\% nonmuscle). Taken together, these data suggest that Lin-28 has an important and tissuespecific function in muscle.

We used a proteomic affinity-based approach to identify protein partners of Lin-28 in proliferating and differentiating myoblasts. These studies indicate that Lin-28 is involved in post-transcriptional regulation of insulinlike growth factor 2 (IGF-2), a factor crucial for the growth and differentiation of muscle tissue. Lin-28 complexes contain factors involved in translational initiation and elongation, as well as $5^{\prime}$ cap- and poly(A)-binding proteins. In differentiating myoblasts, Lin-28 is associated with the polysomal compartment. During differentiation, induction of Lin-28 results in an increased number of ribosomes per molecule of IGF-2 mRNA, as demonstrated by sucrose gradient experiments. Conversely, in PMs depleted of Lin-28 by RNAi, mRNA of IGF-2 fails to shift to the polysomal fraction, leading to a decrease in the rate of synthesis of IGF-2 protein. Moreover, during oxidative stress, endogenous Lin-28 follows the translation initiation factors into the stress granules (SGs), cytoplasmic structures that contain temporally inactive mRNA translation initiation complexes. These observations further confirm the in- teraction of Lin-28 with translation initiation complexes during myogenic differentiation. Finally, Lin-28 was shown to increase the translation of an IGF-2 reporter construct in vitro. We propose that the decrease of general transcriptional activity that occurs upon terminal muscle differentiation is partially compensated by "translation enhancer" proteins, such as Lin-28, that allow the maturing skeletal muscle fibers to produce the necessary proteins from low amounts of available mRNA.

\section{Results}

\section{Lin-28 is induced during myogenic differentiation}

As a first approach toward understanding the function of Lin-28 in skeletal muscle, we have analyzed the expression of Lin-28 protein in mouse PMs in culture, and in regenerating muscle fibers in vivo. In adult PMs, Lin-28 is barely detectable during proliferation, but is dramatically up-regulated during terminal differentiation (Fig. 1A, lanes 1,2). Lin-28 is strongly expressed in freshly isolated embryonic and fetal PMs during proliferation and differentiation, but is not detectable in embryonic rhabdomyosarcoma (RMS) cells (Fig. 1A; data not shown). Detailed analysis of the kinetics of terminal differentiation of adult PMs in vitro showed that Lin-28 is induced as early as $24 \mathrm{~h}$ post-differentiation signal, and remains high as late as $7 \mathrm{~d}$ of differentiation (Fig. 1B). Differentiation was monitored by the detection of muscle creatine kinase (MCK), a specific muscle marker. Interestingly, the microRNA miR-125b, which has been shown to suppress Lin-28 in C. elegans and in some mammalian cells, is down-regulated during terminal differentiation of PMs (Fig. 1B, bottom panels). This observation suggests that the control of Lin- 28 by miR-125b (lin-4 in nematodes) is a conserved mechanism (Moss et al. 1997; Bagga et al. 2005; Wu and Belasco 2005).

Immunofluorescence analysis indicated that, in differentiated myotubes, Lin-28 is abundant in the cytoplasm, but also shows nucleolar staining in $10 \%-15 \%$ of the nuclei (Fig. 1C). In vivo, however, Lin-28 is little expressed in resting muscle, but it is strongly up-regulated during regeneration of skeletal muscle fibers. Lin-28 expression decreases when the regeneration is histologically and functionally complete, and the fibers no longer express embryonic myosin heavy chain (MHC), the marker of actively regenerating muscle (Fig. 1D).

Proliferating ES cells have been described to express Lin-28, and the protein was found to be gradually downregulated during spontaneous or RA-induced differentiation of EBs (Richards et al. 2004; Lee et al. 2005). However, in such EBs, the percentage of myogenic differentiation is low (typically, $0 \%-5 \%$ ). To obtain an ES cell model that is more quantitatively determined toward a myogenic fate, we have stably expressed low amounts of the myogenic transcription factor MyoD in a population of ES cells (Duquet et al. 2006). MyoD-ES cells can be aggregated into EBs that rapidly differentiate into multinuclear, contracting, MHC-expressing muscle fibers (Fig. 1E). In sharp contrast to control ES cells, where Lin-28 expression is down-regulated during differentiation of 
A

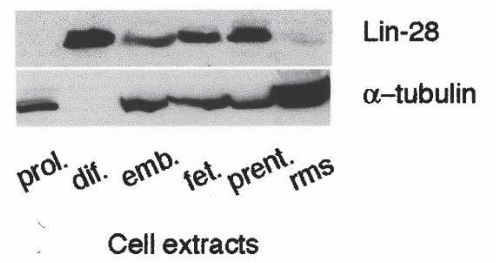

B

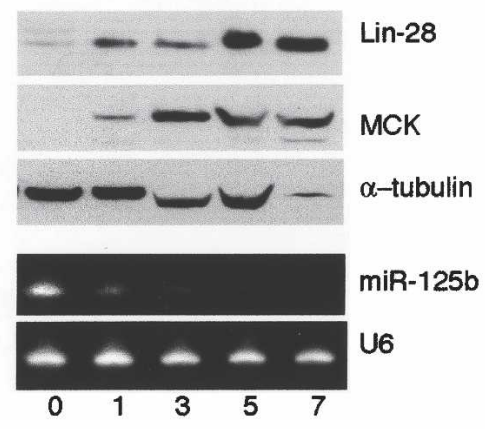

Differentiation, days

C

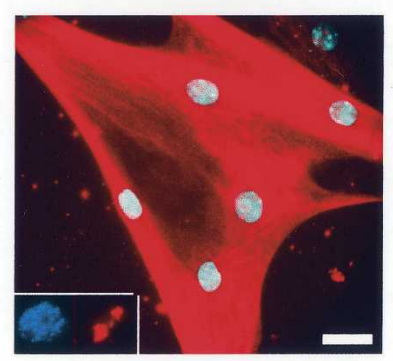

Lin-28/DAPI, 96h differentiation

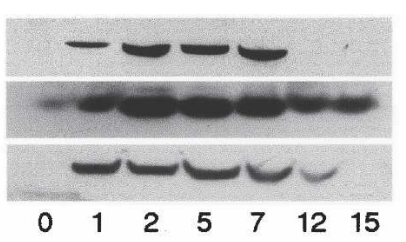

embMHC

Lin-28

$\alpha$-tubulin

Regeneration, days

$E$

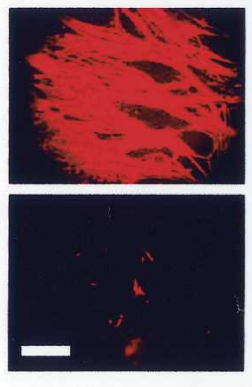

MHC

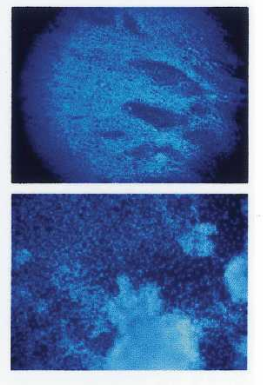

DAPI
$\mathrm{F}$

\section{ES-MyoD}

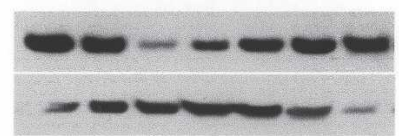

Lin-28

$\alpha$-tubulin

ES control

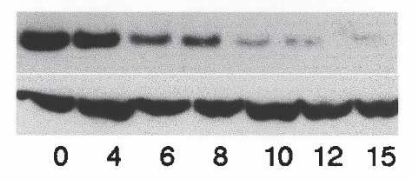

Lin-28

$\alpha$-tubulin

Figure 1. Lin-28 is induced during myogenic differentiation. $(A)$ Western blot showing expression of Lin-28/tubulin in the following cells: (prol.) adult PMs, proliferation; (dif.) adult PMs, differentiation $10 \mathrm{~d}$ (note the absence of tubulin, typical for mature myotubes); (emb.) embryonic mouse PMs (14.5 d); (fet.) fetal mouse PMs (18.5 d); (prent.) prenatal mouse PMs (20.5 d); (rms) embryonic RMS cells. (B) Kinetics of differentiation of PMs. (Top panels) Western blot. (Bottom panels) Northern blot. $(C)$ Expression and subcellular localization of Lin-28 in differentiated PMs. (Inset) Nucleolar expression of Lin-28. Bar, $10 \mu \mathrm{m}$. $(D)$ Western blot showing expression of Lin-28 during cardiotoxin-induced regeneration of TA muscle. (embMHC) Embryonic MHC, control of regeneration efficiency. $(E)$ Induction of the myogenic marker MHC in control and MyoD-expressing ES cells, $15 \mathrm{~d}$ of differentiation of EBs. Bar, $200 \mu \mathrm{m} .(F)$ Kinetics of expression of Lin-28 in differentiating ES-MyoD and control ES cells (Western blot).

EBs, as previously described, Lin-28 expression in MyoDES cells was reinduced at terminal stages of differentiation into myotubes (Fig. 1F).

Taken together, these observations suggest that Lin-28 protein has a function in terminal muscle differentiation.

Expression of Lin-28 in myoblasts increases the differentiation efficiency

The $\mathrm{C} 2 \mathrm{C} 12$ mouse myoblast cell line originates from PMs isolated from adult mouse leg muscle (Yaffe and
Saxel 1977). C2C12 cells have retained the ability to differentiate into multinucleated myotubes, and are widely used as an in vitro model for muscle differentiation, although this process is much less efficient in $\mathrm{C} 2 \mathrm{C} 12 \mathrm{~s}$ than in PMs. C2C12 myoblasts are immortalized, aneuploid, and phenotypically different from freshly isolated PMs (our observations). The level of endogenous Lin-28 in the $\mathrm{C} 2 \mathrm{C} 12$ cell line is very low to undetectable, with a weak up-regulation during terminal differentiation (data not shown).

C2C12 cells were chosen to explore Lin-28 function in myogenesis using a gain-of-function assay. Lin-28 fused 
Polesskaya et al.

to GFP was stably expressed in C2C12 myoblasts. Transfected cells were then FACS-sorted into three populations, according to the levels of Lin-28-GFP. Differentiation of these cell populations was evaluated by monitoring the expression of MCK (Fig. 2A) and MHC (Fig. 2B). The results show that high, but not low and medium, expression of Lin-28 leads to a significant increase of muscle differentiation efficiency, both at the level of expression of myogenic markers (MCK), and at the level of size of myotubes at $2 \mathrm{~d}$ of differentiation (Fig. 2B).

Differentiating PMs express high levels of endogenous Lin-28. A loss-of-function RNAi assay using two different small interfering RNAs (siRNAs) directed against Lin-28 clearly showed that induction of Lin-28 is essential for differentiation. Down-regulation of Lin-28 dramatically impairs the differentiation of PMs isolated from adult leg muscle (Fig. 2C), or from adult diaphragm (Supplementary Fig. 1). PMs differentiating in the absence of Lin-28 express detectable levels of specific markers of late myogenic differentiation (MHC), but show a marked defect in fusion and formation of multinuclear myotubes. The efficiency of myogenesis was quantified in gain- and loss-of-function assays using the fusion index (average number of nuclei per myotube) (see Fig. 2B,C, insets).

We have analyzed the involvement of known functional domains of Lin-28 in regulation of skeletal myogenesis. In nematodes, four distinct missense mutations of highly conserved amino acids within the RNA-binding CSD domains have been shown to cause loss of function of Lin-28 (Moss and Tang 2003). In order to find out whether in mammalian muscle the function of Lin-28 depends on these conserved regions, these mutations, as well as others, were introduced into human recombinant Lin-28 that was subsequently used to establish C2C12 myoblast cell lines. Analysis of the resulting myoblast cell lines showed that point mutations and/or deletions of conserved amino acids in the CSD domains, but not in

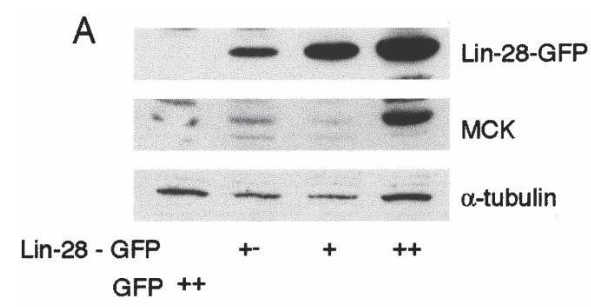

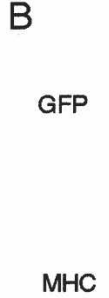

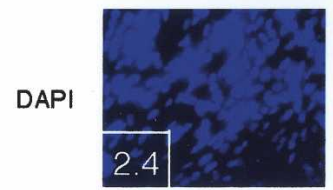

Lin-28 - GFP GFP
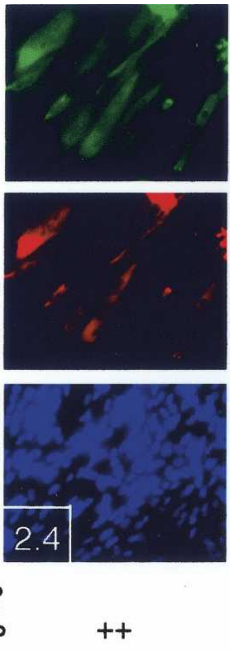
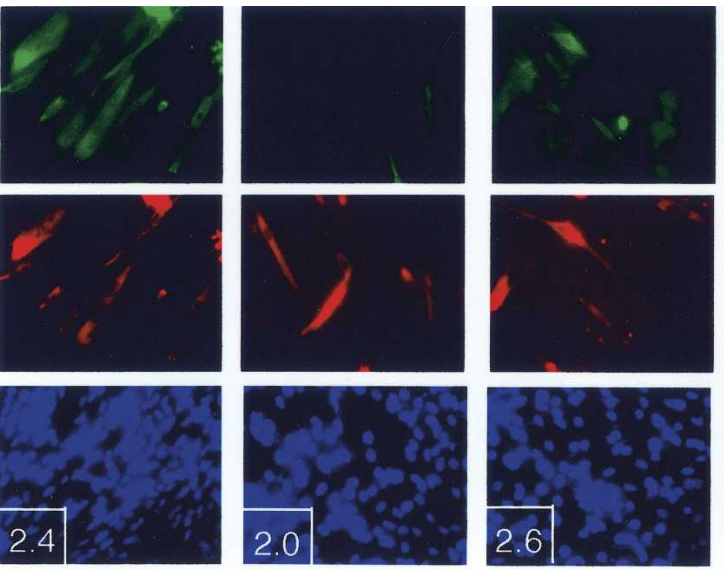

$+$

$+$
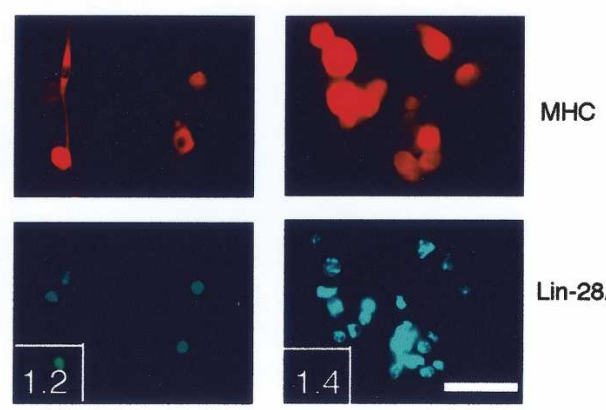

Lin-28/1

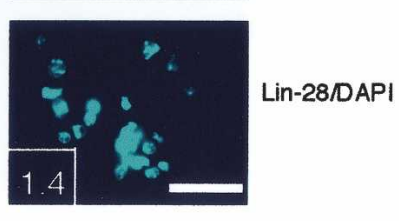

Lin-28/2
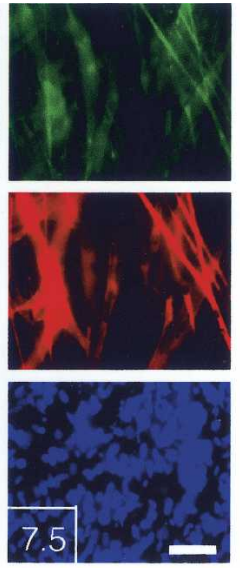

$++$

Differentiation, $5 d$

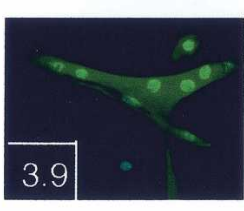

SIRNA:

control

Figure 2. Expression of Lin-28 in myoblasts increases the differentiation efficiency. $(A, B)$ Increase of differentiation efficiency of C2C12 myoblasts overexpressing Lin-28-GFP. C2C12-Lin-28-GFP cells were FACS-sorted into the following fractions: low (+-), medium $(+)$, and high $(++)$. (Control) GFP-expressing C2C12. Levels of recombinant Lin-28 in the "high" fraction were comparable with levels of endogenous Lin-28 in differentiated adult PMs (data not shown). Differentiation at $48 \mathrm{~h}$ was evaluated by Western blot of MCK expression $(A)$ or by immunostaining for $\mathrm{MHC}(B)$. (Insets) Fusion index (number of nuclei per myotube). Bar, 50 um. $(C)$ Immunostaining of adult mouse PMs at $5 \mathrm{~d}$ of differentiation following transfection with control siRNA or siRNAs directed against Lin-28. (Insets) Fusion index (number of nuclei per myotube). Bar, $50 \mu \mathrm{m}$. (D) Western blot analysis of the expression of endogenous Lin-28 in the differentiating PMs shown in $C$. 
the ZFMs, leads to erroneous subcellular localization of Lin-28 (Supplementary Fig. 2A). Moreover, the expression of CSD-mutated Lin-28 was not sustained over a 2 -wk period of cell culture, and there was no positive effect of these mutants on terminal myogenic differentiation, contrary to the wild-type Lin-28, and to the ZFM mutant (data not shown). These results show that the conserved RNA-binding CSD domains of Lin-28 are required for the function of Lin-28 in muscle differentiation.

Lin-28 binds to RNA-containing translation initiation complexes in muscle cells

Using a HA-Flag double affinity-purification technique and proteomic analysis, we have purified and characterized proteins that bind to HA-Flag-tagged Lin-28 ectopically expressed in $\mathrm{C} 2 \mathrm{C} 12$ myoblasts. Consistent with data obtained by overexpressing Lin-28-GFP, expression of similar levels of recombinant HA-Flag-tagged Lin-28 significantly increased the efficiency of differentiation of C2C12 myoblasts (data not shown). Mass spectrometry analysis showed that the most prominent members of Lin-28 complexes are mRNA-binding proteins [poly(A)binding protein, 5' cap-binding protein, nucleolin, hnRNP-F, H1, and IGF-2 mRNA-binding proteins (IMPs) 1,2 , and 3], structural ribosomal proteins, eIF3 $\beta$ translation initiation factor, and elongation factors (EF1- $\alpha$ and EF1- $\alpha 2)$, as well as cytoskeletal and structural proteins $(\alpha-$ and $\beta$-tubulin, muscle and nonmuscle actin and myo- sin). A nonexhaustive list of Lin-28 partners in proliferating and differentiating $\mathrm{C} 2 \mathrm{C} 12$ myoblasts is presented in Table 1.

Treatment of cell extracts prior to affinity purification of Lin-28 complexes, as well as treatment of live, permeabilized C2C12 myoblasts with RNase A, lead to almost complete dissociation of Lin-28 complexes (Fig. 3A,B) and to the disappearance of Lin-28 from cytoplasm and nucleoli (Supplementary Fig. 2B). Thus, Lin-28 complexes are RNA dependent, and the subcellular localization of Lin-28 in myoblasts depends mostly on RNA, and much less on the protein partners of Lin-28. However, the interaction of Lin-28 with the translational initiation factor eIF3 $\beta$ was never completely abolished by RNase A, in contrast to interactions with other mRNA-binding proteins, such as IMPs (Fig. 3B).

Taken together, our data on Lin-28 protein partners suggested that Lin-28 in myoblasts is associated with translationally active polysomes. In order to test this hypothesis, we performed sucrose gradient experiments to analyze the subcellular distribution of HA-Flag-Lin-28 during proliferation and differentiation of C2C12 myoblasts. The results presented in Figure $3 \mathrm{C}$ show that stably expressed Lin-28 is predominantly found in monosomal fractions from proliferating $\mathrm{C} 2 \mathrm{C} 12$ cells. However, there is a clear shift toward the polysomes at $48 \mathrm{~h}$ of differentiation (Fig. 3C). These results were confirmed in differentiating PMs, where endogenous Lin-28 is mostly polysomal (Fig. 3D). The polysomal localization of both ectopic and endogenous Lin-28 is completely

Table 1. A nonexhaustive list of proteins detected in Lin-28 complexes in proliferating or differentiating C2C12 myoblasts, treated or not with RNase $A$

\begin{tabular}{|c|c|c|c|c|}
\hline Proteins & $\begin{array}{l}\mathrm{C} 2 \mathrm{C} 12 \\
\text { proliferating } \\
+ \text { RNase }\end{array}$ & $\begin{array}{c}\mathrm{C} 2 \mathrm{C} 12 \\
\text { proliferating }\end{array}$ & $\begin{array}{c}\mathrm{C} 2 \mathrm{C} 12 \\
\text { differentiating for } \\
72 \mathrm{~h}+\mathrm{RNase}\end{array}$ & $\begin{array}{c}\mathrm{C} 2 \mathrm{C} 12 \\
\text { differentiating } \\
\text { for } 72 \mathrm{~h}\end{array}$ \\
\hline Acta 2 protein & + & + & + & + \\
\hline$\beta$-Actin & + & + & + & + \\
\hline Skeletal muscle actin & + & + & + & + \\
\hline Myosin light and heavy chain & + & + & + & + \\
\hline Tubulin $\alpha$ and $\beta$ & + & + & + & + \\
\hline Poly(A)-binding protein & - & + & - & + \\
\hline CSD-containing protein & - & + & - & + \\
\hline $5^{\prime}$ cap-binding protein & - & - & - & + \\
\hline HNRNP h1 & - & + & - & + \\
\hline HNRNP f & - & + & + & + \\
\hline eEF $1 \alpha$ and $\alpha-2$ & - & + & - & + \\
\hline Nebulin & - & - & + & + \\
\hline Nucleolin & - & + & - & - \\
\hline Ribosomal proteins $60 \mathrm{~S}$ & - & - & - & + \\
\hline Ribosomal protein $26 \mathrm{~S}$ & - & - & - & + \\
\hline Ribosomal protein $40 \mathrm{~S}$ & - & + & - & + \\
\hline Ribosomal protein L7 & - & - & - & + \\
\hline Ribosomal protein 39S & - & + & - & + \\
\hline Ribonuclear protein ronrp & - & + & - & + \\
\hline ATP synthase $\alpha$ chain & - & - & - & + \\
\hline ADP/ATP translocase 1 & - & - & - & + \\
\hline IMP $1-3$ & - & + & - & - \\
\hline RNA-binding protein musashi & - & - & _- & + \\
\hline
\end{tabular}


Polesskaya et al.

A
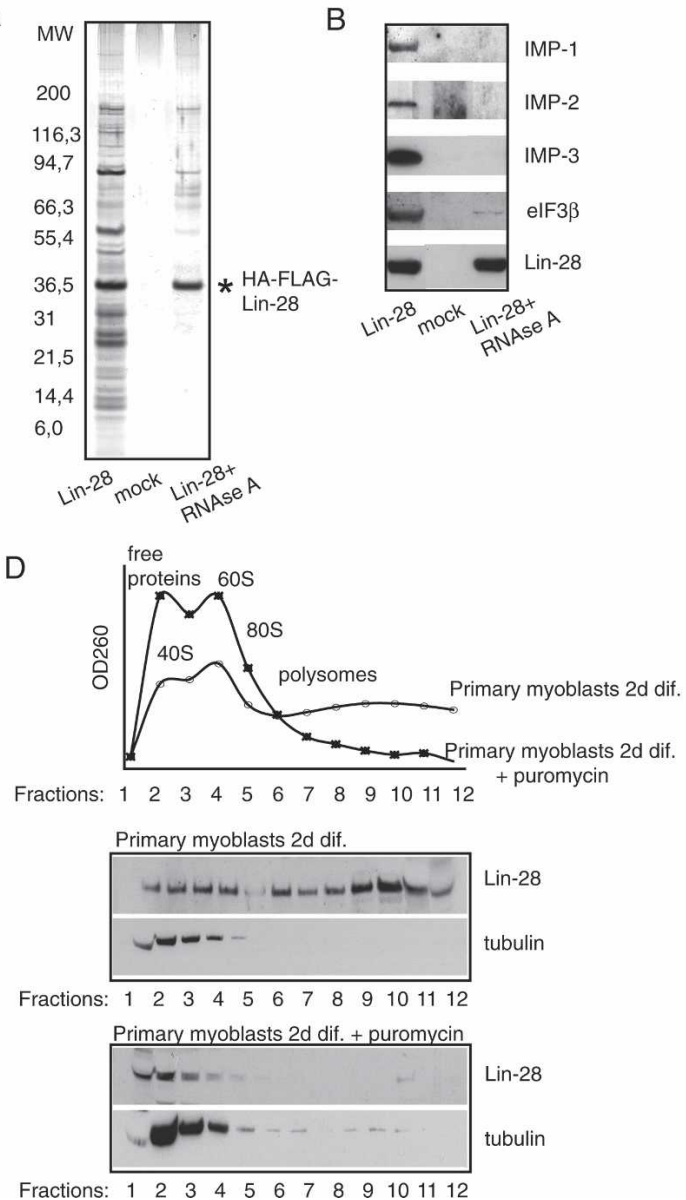
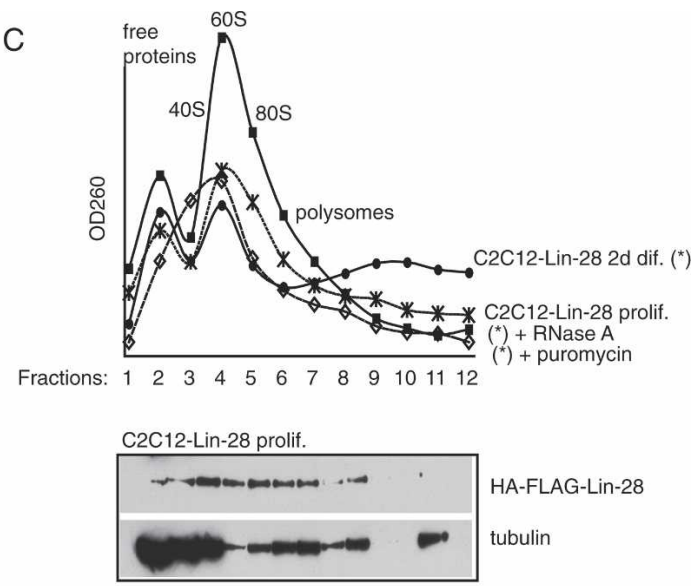

Fractions: $\begin{array}{lllllllllllll}1 & 2 & 3 & 4 & 5 & 6 & 7 & 8 & 9 & 10 & 11 & 12\end{array}$ C2C12-Lin-28 2d dif.

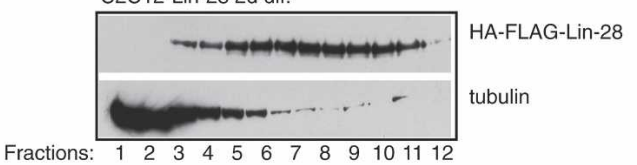

C2C12-Lin-28 2d dif. + puromycin

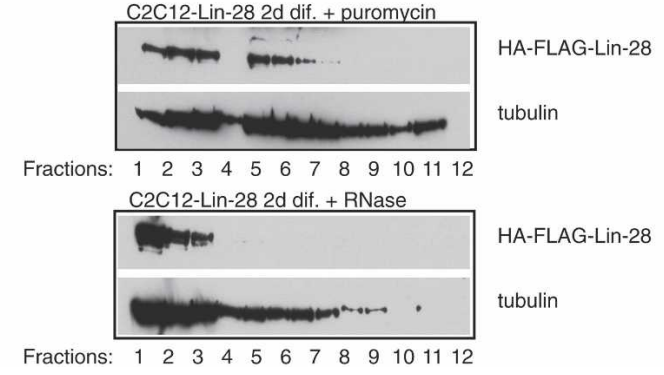

Figure 3. Lin-28 binds to RNA-containing translation initiation complexes in muscle cells. (A) HA-Flag-Lin-28 complexes from proliferating $\mathrm{C} 2 \mathrm{C} 12$ myoblasts were separated on a 4\%-12\% SDS-PAGE and visualized using a silver staining. (Lane 1) Lin-28 complexes from C2C12-HA-Flag-Lin-28 cells. (Lane 2) Mock, control C2C12 cells. (Lane 3) Eluted Flag-Lin-28 complexes were treated with $1 \mathrm{mg} / \mathrm{mL}$ RNase A prior to incubation with HA-agarose beads (see Materials and Methods). (B) Western blot analysis of proteins interacting with Lin-28 in C2C12 myoblasts (lanes as in A). (C) Lin-28 shifts to polysomal fractions during myogenic differentiation. (Top panel) C2C12 extracts were fractionated on a $21 \%-47 \%$ sucrose gradient, and the $\mathrm{OD}_{260} \mathrm{~nm}$ was determined for each 1 -mL fraction. (Bottom panels) Distribution of Lin-28 in fractions of the sucrose gradient; extracts of C2C12-Lin-28 in proliferation or $2 \mathrm{~d}$ of differentiation, treated or not with $10 \mathrm{mM}$ puromycin or $1 \mathrm{mg} / \mathrm{mL}$ RNase A, as indicated. $(D)$ Sucrose gradient separation (as in $C$ ) of extracts from PMs, $2 \mathrm{~d}$ of differentiation, treated or not with $10 \mathrm{mM}$ puromycin.

abolished by puromycin or RNase A treatment (Fig. 3C,D).

\section{Lin-28 colocalizes and interacts with eIF3 $\beta$ in differentiating myoblasts}

To evaluate the interaction between the translation initiation factor eIF $3 \beta$ and Lin-28 under physiological conditions, we have immunoprecipitated eIF3 $\beta$ from differentiating PMs and proliferating P19 cells. Lin-28 coprecipitated with eIF3 $\beta$ in these cell extracts, and this interaction was only slightly decreased by RNase A treatment, suggesting that eIF3 $\beta$ and Lin- 28 can interact strongly and directly when endogenous Lin-28 is induced and functional (Fig. 4A; Supplementary Fig. 3A). Interaction with other partners of Lin-28, such as nucleolin, was abolished by RNase A treatment (Fig. 4A).

We have studied the subcellular localization of Lin-28 with regard to eIF $3 \beta$. These experiments were carried out in adult PMs and in P19 cells, under normal conditions or during sodium arsenate-induced oxidative stress, which leads to formation of SGs, temporary mRNA-protein structures that contain reversibly stalled mRNAprotein translation complexes (Anderson and Kedersha 2002; Kedersha and Anderson 2002).

In untreated myoblasts at $4 \mathrm{~h}$ of differentiation, eIF3 $\beta$ and Lin-28 are dispersed in the cytoplasm, and their colocalization is difficult to analyze. However, $30 \mathrm{~min}$ of treatment with sodium arsenate led to formation of SGs that contained eIF3 $\beta$, as previously described (Kedersha et al. 2005), and were $\sim 85 \%$ positive for Lin-28 (Fig. 4B). Moreover, in mature myotubes, where the cytoplasm is structured by the formation of sarcomers, it was possible to detect an almost $100 \%$ colocalization of Lin- 28 with eIF3 $\beta$ (Fig. 4B, middle panel). The formation of SGs depends on the microtubule network (Ivanov et al. 2003), 
A

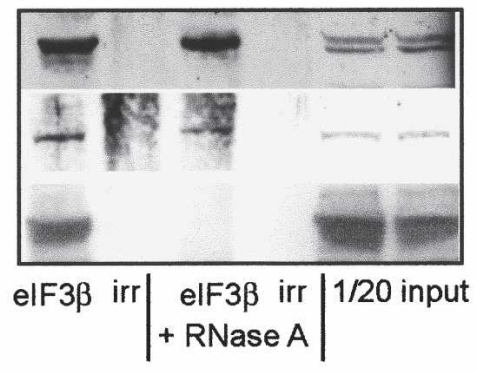

Lin-28

elF3 $\beta$

nucleolin

B
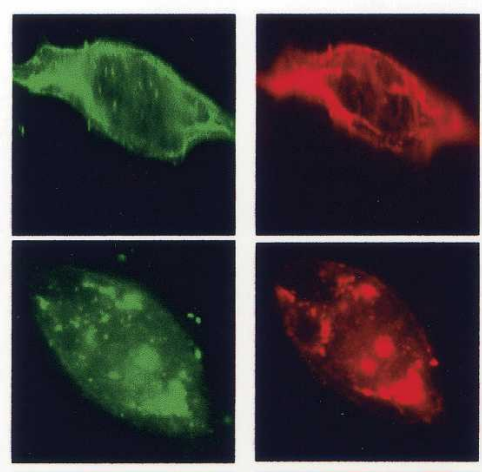

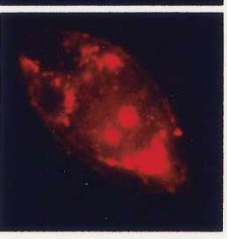

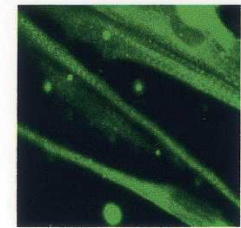

elF3 $\beta$

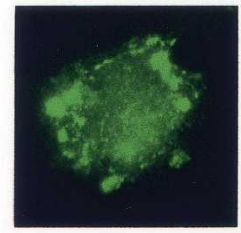

TIA-1

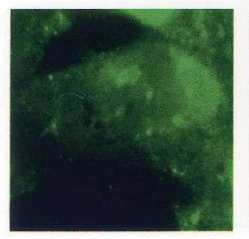

Nucleolin

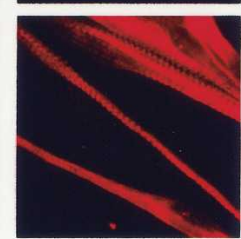

Lin-28

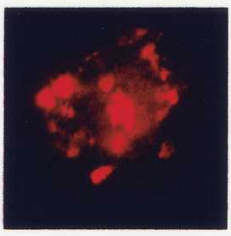

Lin-28

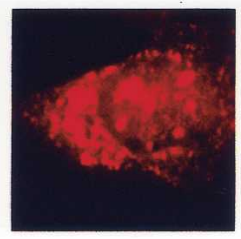

Lin-28
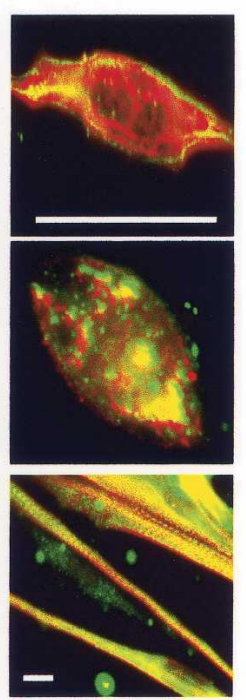

merge

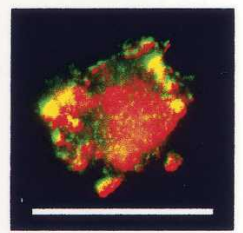

merge

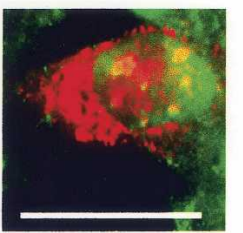

merge 4h differentiation tarsenate 4h differentiation control

4h differentiation +arsenate

96h differentiation

4h differentiation +arsenate

which is irreversibly remodeled during terminal myogenic differentiation; predictably, arsenate treatment of mature myotubes did not lead to formation of SGs /data not shown). In PMs and P19 cells, Lin-28 also colocalized with TIA-1, a known marker of SGs (Kedersha et al. 2005). However, nucleolin, a nucleolar and cytoplasmic protein that interacts with Lin-28, was not detected in SGs, providing a negative control (Fig. 4B, bottom panels; Supplementary Fig. 3B).

These data support the hypothesis that, during skeletal muscle differentiation, Lin-28 is associated with
Figure 4. Lin-28 colocalizes and interacts with eIF3 $\beta$ in differentiating myoblasts. $(A)$ eIF3 $\beta$ coprecipitates with Lin-28 and nucleolin in extracts from PMs, 72-h differentiation time point. Treatment with $1 \mathrm{mg} / \mathrm{mL}$ RNase A prior to immunoprecipitation diminishes the coprecipitation of Lin- 28 with eIF3 $\beta$ by $17 \%$ (Bio Profil quantification) and abolishes the coprecipitation of eIF3 $\beta$ with nucleolin. $(B)$ Colocalization of Lin-28 with eIF3 $\beta$ in the cytoplasm of PMs. (Top panels) Four hours of differentiation, untreated cells, or cells with SGs, induced by $30 \mathrm{~min}$ of treatment with $0.5 \mu \mathrm{M}$ sodium arsenate (oxidative stress). (Middle panel) Ninetysix hours of differentiation, colocalization Lin28 with eIF3 $\beta$ in untreated cells (formation of SGs does not occur in mature myotubes; see the Results). (Bottom panels) Lin-28 colocalizes with SG marker TIA-1, but not with nucleolin, in the cytoplasm of sodium arsenate-treated PMs at $4 \mathrm{~h}$ of differentiation. Bars, $10 \mu \mathrm{m}$. translation initiation complexes in the polysomal compartment.

Lin-28 binds IGF-2 mRNA and increases the efficiency of translation of IGF-2 protein in differentiating muscle cells

Lin-28 complexes purified from C2C12 myoblasts contain proteins of the IMP family, well-characterized mRNA-binding proteins that regulate the expression of IGF-2 at the post-transcriptional level (Nielsen et al. 
1999|. In vivo, this interaction is not likely to be of great physiological importance, given that Lin-28 protein is induced during differentiation of PMs, with a marked peak in late differentiation; IMP proteins, on the contrary, are strongly expressed in proliferating myoblasts, and are rapidly down-regulated at the onset of terminal differentiation (our unpublished data). This complementary expression pattern, which is also reproduced during regeneration of muscle in vivo, does not support the hypothesis that IMP proteins form a long-lasting complex with Lin-28 in muscle. However, coprecipitation of tagged Lin-28 with endogenous IMP proteins in proliferating $\mathrm{C} 2 \mathrm{C} 12$ cells has been an important indication suggesting that Lin-28 can be involved in translational regulation of IGF-2, a growth factor that is necessary and sufficient for skeletal muscle differentiation in vitro and for muscle fiber hypertrophy in vivo (Florini et al. 1991, 1996; Armand et al. 2004). Lin-28 complexes could bind IGF-2 mRNA and possibly regulate the efficiency of muscle differentiation by controlling the synthesis of IGF-2 protein.

In order to test this hypothesis, Lin-28 complexes were purified from proliferating or differentiating $\mathrm{C} 2 \mathrm{C} 12$ myoblasts, and the presence of IGF-2 mRNA was monitored by qRT-PCR using two different sets of primers specific for distinct regions of IGF-2 mRNA (coding region and 5' Leader 3 regulatory sequence). The results revealed an association of IGF-2 mRNA with Lin-28 complexes in myoblasts. Moreover, the number of copies of IGF- 2 mRNA in equal amounts of Lin-28 complexes increased almost 10 -fold by day 2 of differentiation (Fig. 5A, left panel). The mRNA of MyoD was also found associated with Lin-28, but in contrast to IGF-2, this mRNA was not enriched in Lin-28 complexes isolated from differentiating myoblasts (Fig. 5A, middle panel). Comparable levels of induction of total mRNA of IGF-2 and MyoD were confirmed by qRT-PCR, indicating that association of Lin-28 complexes with IGF-2 mRNA is specific, and not due to transcriptional induction of IGF-2 during differentiation (Fig. 5A, right panel).

This result raised the possibility that Lin- 28 can drive the IGF-2 mRNA into polysomes upon differentiation. To test this hypothesis, we monitored the association of IGF-2 mRNA with polysomes during the differentiation of Lin-28-overexpressing C2C12 myoblasts, as well as in PMs, in which endogenous Lin-28 is induced during differentiation. Quantification of the number of copies of IGF-2 mRNA by qRT-PCR in monosomal, light polysomal, and heavy polysomal fractions showed a $10 \%$ shift of IGF- 2 mRNA toward heavy polysomal fractions in C2C12-Lin-28 myoblasts, compared with control C2C12 cells (Fig. 5B, top panel). In a complementary loss-of-function assay, transfection of differentiating PMs with two distinct siRNAs specific for Lin-28, or a control siRNA, led to accumulation of IGF-2 mRNA in the polysomal fraction in control PMs, but not in Lin28-depleted cells (25\%-35\% difference) (Fig. 5C). The effect of Lin-28 expression on the accumulation of mRNA of IGF- 2 in the polysomal fractions was much more dramatic in PMs than in C2C12 myoblasts, suggesting that the translational regulation mechanisms, which have been lost during the transformation of PMs into an immortal $\mathrm{C} 2 \mathrm{C} 12$ cell line, cannot be fully restored by ectopic expression of Lin-28 in C2C12 myoblasts.

In these assays, IGF-2 mRNA was also detected by Northern blot, a less sensitive approach that nevertheless demonstrated the integrity of $4.4-\mathrm{kb}$ IGF-2 transcripts extracted from $\mathrm{C} 2 \mathrm{C} 12$ and PMs, and corresponding to Leader 3 mouse IGF-2 transcript (Rotwein and Hall 1990; Hansen et al. 2004). Taken together, these results show the importance of Lin-28 in the association of IGF-2 mRNA with polysomes.

\section{Lin-28 regulates the expression of IGF-2 and is indispensable for efficient differentiation of skeletal myoblasts}

Our data suggest that regulation by Lin-28 increases the synthesis of IGF-2 protein at the translational level by increasing the number of initiation events, reflected by an increased number of ribosomes per molecule of IGF-2 mRNA. Consistently, in an in vitro translation system, recombinant Lin-28, but not a control irrelevant protein, increased the synthesis of luciferase from an IGF-2-luc reporter construct (regulatory region of the human IGF-2 Leader 3 transcript, 1164 base pair [bp], inserted between the $\mathrm{T} 7$ promoter and the luciferase gene in the pCDNA 3.1 vector; a kind gift from Dr. J. Christiansen), but not from a control reporter differing by the absence of the IGF-2 regulatory region (Fig. 6A). These results further suggest that Lin-28 can increase IGF-2 synthesis by a mechanism involving translational regulation.

Consistent with this hypothesis, we found that the expression of IGF-2 protein in differentiating C2C12 myoblasts ectopically expressing Lin-28 was dramatically increased compared with C2C12 controls, whereas the total amount of IGF-2 mRNA did not vary considerably in these two cell populations (Fig. 6B).

Using two distinct neutralizing antibodies specific for IGF-2, we showed that the increased secretion of biologically active IGF-2 is the main cause of Lin-28's effect on differentiation of $\mathrm{C} 2 \mathrm{C} 12$ myoblasts. Conditioned medium from C2C12 cells overexpressing Lin-28 was transferred onto differentiating control C2C12 myoblasts, in the presence of anti-IGF- 2 antibodies, or of control antibodies, and differentiation was evaluated at the 6-h and 12-h time points (Fig. 6C). Early time points were chosen in order to study the effects of IGF-2 contained in the conditioned medium, and to avoid the secondary effects of neutralizing the endogenous IGF-2, which normally is produced by differentiating control C2C12 from $20 \mathrm{~h}$ onward (our unpublished data). Conditioned media from cells overexpressing Lin-28 had a positive effect on myogenic differentiation, and this effect was completely abolished by the presence of antibodies specific for IGF2. Thus, Lin-28 appears to participate in the differentiation program through induction of IGF-2 secretion.

This hypothesis was confirmed by loss-of-function assays. Similar to C2C12 myoblasts, PMs did not undergo significant transcriptional regulation of IGF-2 when ex- 

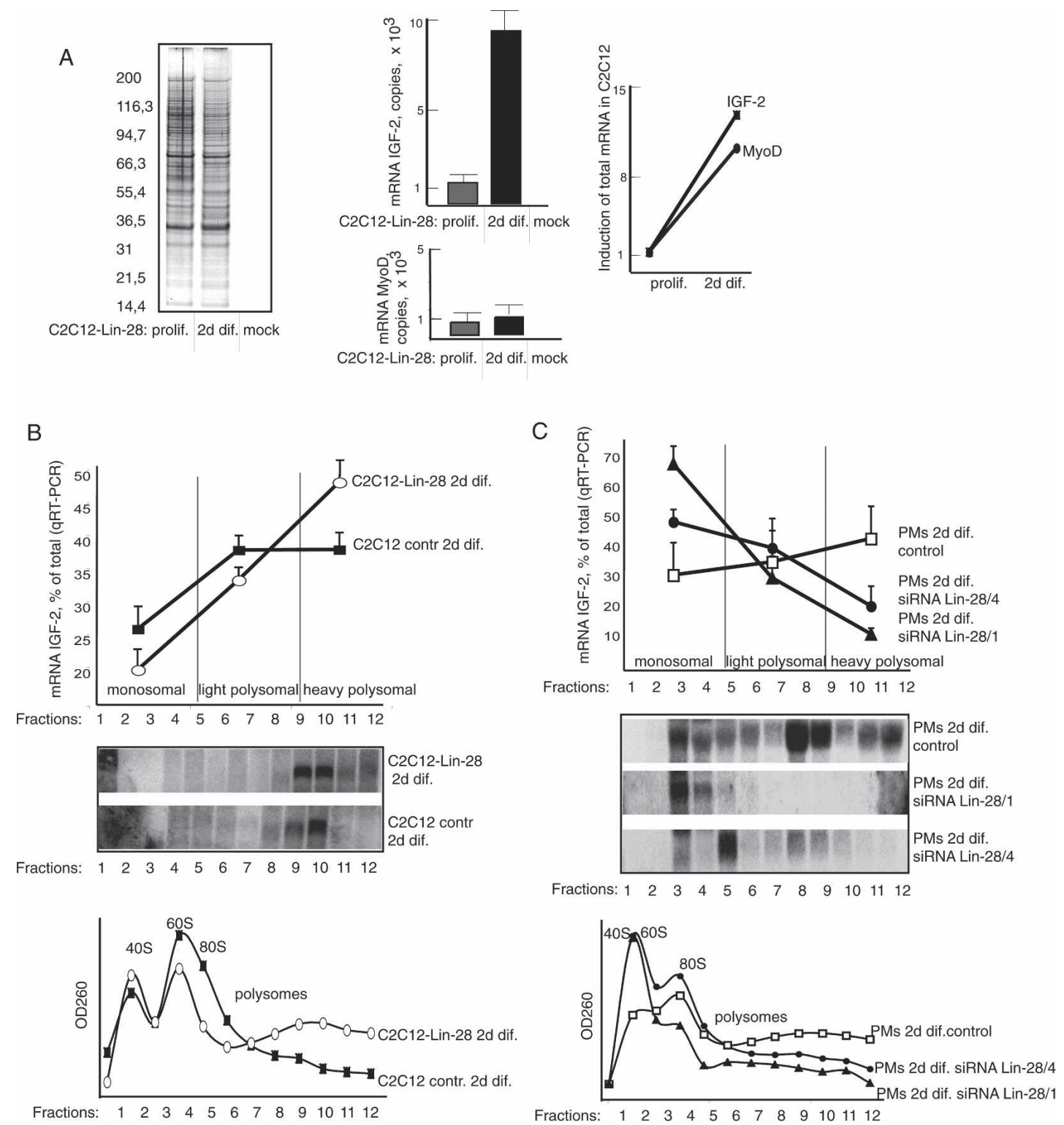

Figure 5. Lin-28 binds IGF-2 mRNA and increases the efficiency of translation of IGF-2 protein in differentiating muscle cells. (A) The quantity of IGF- 2 mRNA bound to Lin- 28 complexes increases 10-fold during $48 \mathrm{~h}$ of differentiation. (Left panel) Normalization of Lin-28 complexes in proliferating and differentiating C2C12-Lin-28 myoblasts. (mock) Control C2C12 cells. (Middle panels) qRT-PCR quantifications of IGF-2 and MyoD mRNAs within Lin-28 complexes. (Right panel) Fold induction of total IGF-2 and MyoD mRNA in differentiating C2C12 myoblasts, qRT-PCR. $(B)$ Expression of Lin-28 leads to a shift of IGF-2 mRNA to "heavy" polysomal fractions. Extracts from C2C12-Lin-28 or C2C12 control myoblasts at the 48-h differentiation time point were fractionated on a $21 \%-47 \%$ sucrose gradient. The $\mathrm{OD}_{260} \mathrm{~nm}$ was determined for each 1-mL fraction, and the number of copies of IGF- 2 mRNA relative to input was quantified for each fraction. Shown is the relative percentage of IGF-2 mRNA in monosomal, light polysomal, and heavy polysomal fractions, and the Northern blot analysis using a probe for the coding region of IGF-2. (C) Induction of endogenous Lin-28 in differentiating PMs is indispensable for shifting of IGF-2 mRNA into "heavy" polysomal fractions. The same analysis as in $B$ was applied to differentiating PMs depleted or not of Lin-28 by indicated siRNAs.

pression of Lin-28 was modified by four distinct siRNAs (qRT-PCR and Northern blot analysis) (Fig. 6D). Consistent with the role of Lin-28 as a translational enhancer of IGF-2, the rate of IGF-2 protein synthesis in PMs depleted of Lin-28 and placed in differentiation conditions was significantly decreased as compared with control PMs (a pulse label assay) (Fig. 6E).
Steady-state levels of IGF-2 protein in PMs were also reduced by down-regulating Lin-28 with siRNAs, and this effect was dose-dependent: Anti-Lin-28 siRNA 1, which leads to leads to an $85 \%$ reduction of Lin-28, abolished IGF-2 induction, whereas siRNA 2, which only reduces Lin- 28 to $\sim 40 \%-50 \%$, had a partial effect (Fig. $6 \mathrm{~F})$. Moreover, the overall efficiency of myogenic differ- 
Polesskaya et al.

A

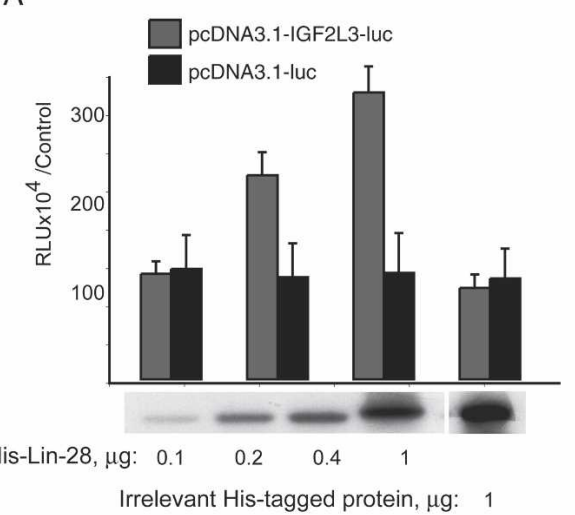

C

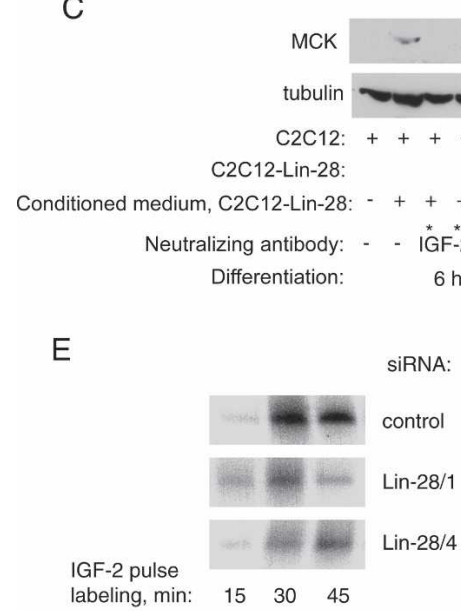

$\mathrm{B}$
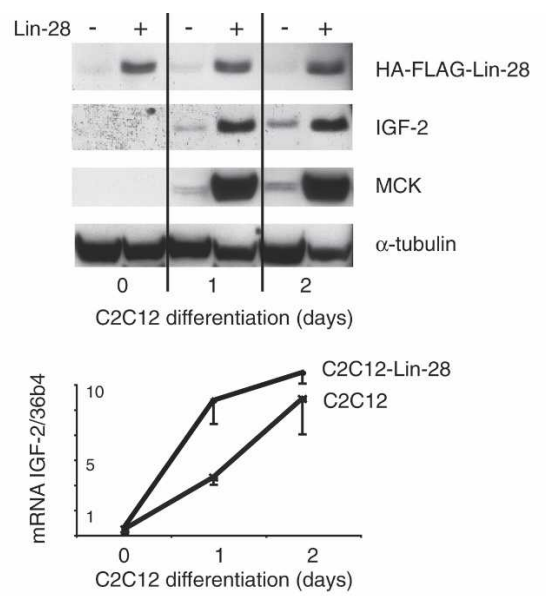

D

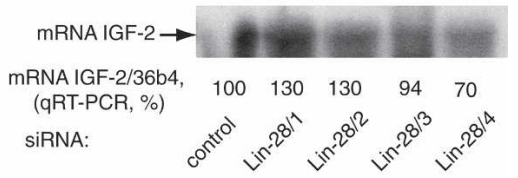

$\mathrm{F}$

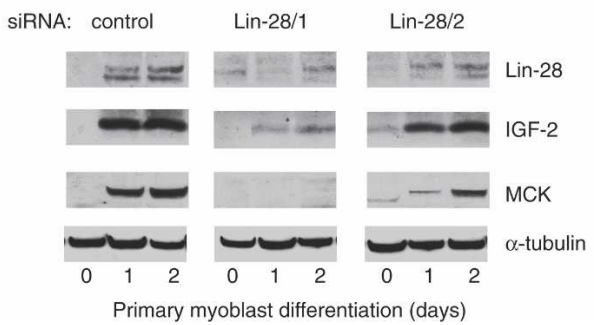

Figure 6. Lin-28 regulates the expression of IGF-2 protein and is indispensable for efficient differentiation of skeletal myoblasts. (A) In vitro translation efficiency increases with the addition of increasing amounts of recombinant Lin-28 to the translation reaction. (Reporter construct) pcDNA3.1-IGF-2-L3-luc or pcDNA3.1-luc (see Materials and Methods). (B) Western blot analysis of expression of Lin-28, IGF-2, and MCK in C2C12-Lin-28 or C2C12 myoblasts at 24 and 48 h of differentiation. (Bottom panel) qRT-PCR quantification of total mRNA of IGF-2 in the same cells. $(C)$ Neutralizing antibodies to IGF-2 abolish the differentiation-stimulating effect of conditioned media from differentiating C2C12-Lin-28 myoblasts. (Lanes 1-5) C2C12 myoblasts, conditioned media from C2C12 (lane 1), C2C12-Lin-28 (lanes 2-5), and C2C12-Lin-28 myoblasts (lane 6) (positive control). Antibodies used were (IGF-2*) S1F2 (Upstate Biotechnology), $10 \mu \mathrm{g} / \mathrm{mL}$; (IGF-2**) AF792 (R\&D Systems), $5 \mu \mathrm{g} / \mathrm{mL}$; (irr.) irrelevant, mixture of antibodies isotype-matched to the IGF-2 antibodies. $(D)$ Northern blot analysis and qRT-PCR quantification of mRNA of IGF-2 in PMs treated with four distinct siRNAs and differentiated for $72 \mathrm{~h}$; normalization, 36b4. (E) Pulse label assay of rate of synthesis of IGF-2 protein in PMs treated with anti-Lin-28 siRNA or control siRNA. Cells were labeled with ${ }^{35} \mathrm{~S}$-methionine for the indicated periods of time and lysed as described in Materials and Methods. IGF-2 protein was then immunoprecipitated and subjected to SDS-PAGE, followed by autoradiography. $(F)$ Western blot analysis of kinetics of differentiation in PMs transfected with control siRNA, or with siRNA 1 and 2 directed against Lin-28.

entiation, as monitored by MCK expression, closely reflected the levels of Lin-28 and of IGF-2 expressed in differentiating PMs (Fig. 6F). These data confirm that control of IGF-2 protein synthesis is one of the principal mechanisms of Lin-28-dependent regulation of skeletal muscle differentiation.

\section{Discussion}

RNA-binding proteins are important regulators of cell determination, differentiation, motility, and other pro- cesses, during embryogenesis and adult life. Lin-28, a highly conserved RNA-binding protein with a complex mechanism of regulation both in nematodes and in higher species, has an interesting pattern of expression, which does not immediately indicate a specific function in a particular physiological process. Lin-28 is abundant in ES cells and ECs of different origins, and appears to be down-regulated during RA-induced neuronal differentiation of these pluripotent cells, suggesting a function associated with "stemness." However, Lin-28 is also detected in specific fully differentiated tissues, the adult 
cardiac and skeletal muscle, suggesting that this protein can have a specific function in these tissues and organs.

We now show that, during terminal differentiation of skeletal muscle, Lin-28 can act as a "translational enhancer," driving specific mRNAs to polysomes and thus increasing the efficiency of protein synthesis. Such mechanisms of translational regulation can be important for myogenesis, given that formation of adult skeletal muscle fibers is generally associated with a decrease of general transcriptional activity, with lower levels of total mRNA, as well as with remodeling and condensation of chromatin in the nuclei that become irreversibly postmitotic (Panar and Nair 1975). We have identified several mRNAs bound by Lin-28 in myoblasts, such as the mRNA of myogenic transcription factor MyoD, of ribosomal protein 36b4, and of Lin-28 itself (our unpublished data). Interestingly, one of the mRNA targets of Lin-28 encodes the cytokine IGF-2. Regeneration of skeletal muscle depends on activation, proliferation, and subsequent differentiation of adult muscle stem cells (satellite cells), which fuse to form new muscle fibers (Morgan and Partridge 2003; Zammit et al. 2006). Maturation of these fibers depends on multiple regulatory mechanisms, and notably on the presence of IGF-2, a growth factor that is indispensable for efficient muscle differentiation in vitro and in vivo (Husmann et al. 1996; Yoshiko et al. 2002). IGF-2 participates in the post-regeneration hypertrophy of skeletal muscle fibers and in the hypertrophy of cardiomyocytes in vitro and in vivo, after a myocardial infarction (DeVol et al. 1990; Adachi et al. 1994; Battler et al. 1995; Huang et al. 2002).

Interestingly, IGF-2 protein remains strongly expressed in fully regenerated skeletal muscle fibers after the decrease of general transcriptional activity has occurred, suggesting that, at this stage, IGF-2 expression may rely on post-transcriptional mechanisms. IGF-2 expression correlates with the presence of Lin-28 (our unpublished data). Our results show that Lin-28 is necessary for the translational up-regulation of IGF-2 expression in cultured myoblasts and has the ability to enhance translation in vitro. Hence we propose that Lin-28 functions as a "translational enhancer," increasing the efficiency of protein synthesis, when the corresponding mRNA is not transcribed anymore and its abundance becomes low. The association of Lin-28 with the translational machinery and mRNAs such as IGF-2 results in an increased number of initiation events per molecule of mRNA, and, indirectly, in stabilizing the mRNAs bound to Lin-28 translation initiation complexes /our unpublished data). Lin-28 itself seems to be regulated at the translational level in differentiating myoblasts, since its expression is inversely correlated with that of the miRNA miR-125b. Moreover, the recruitment of Lin-28 protein to polysomes upon differentiation might also be regulated, since it is increased in myoblasts under differentiation conditions as compared with proliferating cells (Fig. 3C).

Given that Lin-28 is highly expressed in cardiac muscle tissue in mammals (Yang and Moss 2003), it will be interesting to analyze the mechanisms of myocardi- um recovery after an important injury, such as an infarction, to find out whether Lin-28 is also involved in IGF2-dependent post-traumatic hypertrophy of the heart. Moreover, regulation of the insulin/IGF pathway via Lin28 may be a highly conserved mechanism, as suggested by two recent publications showing that the Lin-4/Lin14-Lin-28 regulatory pathway (Seggerson et al. 2002) directly influences insulin-IGF signaling in nematodes (Boehm and Slack 2005; Hristova et al. 2005).

In contrast, Lin-28 does not seem to be implicated in the development of RMS, a pediatric cancer originating from myogenic precursor cells. RMS cells overexpress IGF-2, which acts as an important autocrine factor for their proliferation (Minniti and Helman 1993). However, RMS cells do not express detectable levels of Lin-28, and ectopic expression of Lin-28 in these cells did not lead to terminal muscle differentiation (our unpublished data). These results suggest that Lin-28 is involved in normal skeletal myogenesis, but not in malignant transformation of myogenic cells, and that the up-regulation of IGF-2 in RMS is not due to aberrant regulation of IGF-2 synthesis by Lin-28. Interestingly, although induction of IGF-2 protein occurs on roughly the same level during the differentiation of low-passage PMs or of the immortal, tumorigenic $\mathrm{C} 2 \mathrm{C} 12$ myoblasts, the induction of IGF-2 mRNA is very insignificant in PMs (three- to fivefold), whereas in C2C12 cells, IGF-2 mRNA is induced 10-fold on the first day of differentiation, and up to 90fold at day 6 of differentiation in culture (our unpublished data). These observations further indicate that translational regulation by Lin- 28 may be a characteristic of healthy muscle tissue, whereas transformed cells of muscle origin will preferentially rely on their increased transcriptional activity to produce the necessary cytokines. However, deregulation of the Lin-28 pathway might be involved in development of other human cancers, as suggested by a recent study showing an overexpression of Lin-28 isoforms in human hepatocellular carcinoma (Guo et al. 2006).

The role of Lin-28 in ES and EC cells, and in early embryonic development, remains to be elucidated. However, we have observed interactions between Lin-28 and the translation initiation complexes in P19 EC cells (Supplementary Fig. 3). It was previously demonstrated that expression of IGF-2 in EC cells depends on a translational regulation factor present only in nondifferentiated EC cell system (Teerink et al. 1994). We strongly believe that we have identified this factor, and propose that Lin-28 increases IGF-2 translational efficiency in early embryogenesis, when the cells are relying on the regulated translation of mRNAs to rapidly accomplish the development initiation program (Piccioni et al. 2005). From our data, it is clear that Lin-28 activity is not restricted to IGF-2, and Lin-28 complexes interact with other mRNAs in proliferating and differentiating myoblasts. Elucidation of other targets of Lin-28 translational regulation will undoubtedly point to other pathways controlled by this protein during development and differentiation.

Thus, our results assign the function of a "transla- 
tional enhancer" of protein synthesis to Lin-28, a highly conserved RNA-binding protein, in such physiologically different cells and tissues as the fully differentiated skeletal muscle fibers and the pluripotent ES and EC cells.

\section{Materials and methods}

Detailed experimental protocols are available on request.

Cell culture, stable cell lines, and oxidative stress assays

Cell culture media were purchased from Invitrogen. C2C12 mouse myoblasts were purchased from American Type Culture Collection (ATCC) and cultured as recommended in DMEM supplemented with $15 \%$ fetal calf serum (FCS; PAA). Embryonic and fetal mouse myoblasts were obtained from Pax3-GFP transgenic mice by FACS sorting of dissected muscle from abdomen, diaphragm, and front legs, as described (Montarras et al. 2005). Mouse PMs from adult skeletal muscle were obtained as previously described (Polesskaya et al. 2003), and cultured in Ham's media, 20\% FCS, and $2.5 \mathrm{ng} / \mathrm{mL}$ bFGF (Invitrogen). Differentiation of $\mathrm{C} 2 \mathrm{C} 12$ myoblasts and PMs was induced by transferring the cells to DMEM with 2\% and 5\% horse serum (Invitrogen), respectively. Mouse ES cells and the MyoD-ES cell line were cultured and differentiated as described in Duquet et al. (2006). Embryonic RMS cells were a gift from Dr. S. Leibovich and were cultured in DMEM supplemented with 10\% FCS.

To induce the formation of SGs, PMs or P19 cells were incubated with $0.5 \mu \mathrm{M}$ sodium arsenate for $30 \mathrm{~min}$, fixed for $2 \mathrm{~min}$ in prechilled methanol at $-20^{\circ} \mathrm{C}$, and immunostained. Image analysis was performed on a confocal microscope using standard software.

C2C12 myoblasts were transfected using Lipofectamin (Invitrogen) with the expression vector pCAGI-puro, encoding human Lin-28 (97\% similar to mouse Lin-28) fused to GFP (a kind gift from Dr. E.G. Moss), and the selected stable cell population was FACS-sorted according to the levels of expression of GFPLin-28.

\section{Transfections and RNAi assays}

Transient transfection of PMs was performed using HiPerfect (Qiagen), according to the manufacturer's instructions. siRNA duplexes were transfected at $10 \mathrm{nM}$ overnight, and differentiation was started the next day. The efficiency of RNAi was evaluated by Western blot. The oligonucleotides corresponding to the sense-strand sequences of siRNA were Lin-28/1, r|GGGUUGU GAUGACAGGCAA)dTdT; Lin-28/2, r/CGUGAUGGUUGAU AGCUAA)dTdT; Lin-28/3, r/AAGTGGTTCAACGTGCGCAT G)dTdT; Lin-28/4, r(AACTGCGGTGGGCTAGACCAT)dTdT; and control, Irrelevant siRNA (Qiagen).

\section{Pulse-labeling of IGF-2 in differentiating PMs}

PMs were plated at $1 \times 10^{6}$ per collagen-coated $10-\mathrm{cm}$ dish, and transfected with anti-Lin-28 siRNAs as described above. Eighteen hours later differentiation was induced, and $24 \mathrm{~h}$ after the beginning of differentiation, the cells were transferred to methionine/cysteine-free DMEM (Invitrogen) containing $10 \mu \mathrm{Ci}$ / $\mathrm{mL}\left[{ }^{35} \mathrm{~S}\right]$-methionine (Amersham) for the indicated periods of time. Cells were lysed in $0.4 \mathrm{~mL}$ of buffer containing $50 \mathrm{mM}$ Tris- $\mathrm{HCl}(\mathrm{pH} 7.5), 1 \% \mathrm{NP}-40,150 \mathrm{mM} \mathrm{NaCl}$, and protease inhibitors (Complete; Roche). Lysates were cleared by $10 \mathrm{~min}$ of centrifugation at maximal speed in a table-top centrifuge, and IGF-2 was immunoprecipitated using a mixture of two specific antibodies, as indicated below. Antibody-bound IGF-2 was col- lected on protein A/protein G-coupled Sepharose beads (Sigma), washed five times with lysis buffer, and subjected to SDSPAGE, followed by autoradiography.

\section{Skeletal muscle regeneration assay}

Skeletal muscle regeneration was induced by injecting $10 \mu \mathrm{L}$ of $10 \mu \mathrm{M}$ cardiotoxin (Latoxan) in PBS in Tibialis anterior (TA) muscle of 7- to 8-wk-old C57Bl6 female mice. TA muscle was collected at the indicated time points, and lysed in buffer containing $50 \mathrm{mM}$ Tris- $\mathrm{HCl}(\mathrm{pH}$ 7.4), 0.1\% Triton X-100, $5 \mathrm{mM}$ EDTA, $250 \mathrm{mM} \mathrm{NaCl}$, and protease inhibitors (Complete; Roche). Total muscle lysates were analyzed by Western blot. Expression of embryonic MHC was used as a positive control of regeneration efficiency.

\section{Affinity purification of Lin-28 complexes}

C2C12 myoblasts stably expressing Flag-HA-Lin-28 were obtained using the retroviral vector pOZFHH (kind gift from Dr. V. Ogryzko, described in Viens et al. 2006). Lin-28 complexes were immunoprecipitated from whole-cell extracts (lysis buffer: $10 \%$ glycerol, $20 \mathrm{mM}$ Tris- $\mathrm{HCl}$ at $\mathrm{pH} 8,0.2 \mathrm{mM}$ EDTA, $0.1 \%$ NP-40, 0.5 M KCl, and protease inhibitors [Complete; Roche]) using M2-agarose beads, eluted with Flag peptide, treated or not with $1 \mathrm{mg} / \mathrm{mL}$ protease-free RNase A (Roche), reprecipitated with anti-HA-agarose beads, and eluted with HA peptide, as described in Nakatani and Ogryzko (2003) (all reagents were purchased from Sigma). Complexes were separated on a $4 \%-$ $12 \%$ polyacrylamide gel (Invitrogen), and stained using the Silver Quest kit from Invitrogen, according to the manufacturer's instructions. Mass spectrometry identification of proteins was carried out by Dr. R. Tomaino (Harvard Medical School, Boston, MA).

Purification of RNA from Lin-28 complexes was accomplished by digestion with proteinase $\mathrm{K}$ (Roche; $0.2 \mathrm{mg} / \mathrm{mL}$ in $0.5 \% \mathrm{SDS}, 45 \mathrm{~min}$ at $37^{\circ} \mathrm{C}$ ), followed by phenol-chloroform extraction and ethanol precipitation in the presence of $20 \mu \mathrm{g}$ of glycogen (Invitrogen) per sample.

\section{Immunoprecipitation of eIF3 $\beta$}

Approximately $30 \times 10^{6}$ differentiating PMs were lysed in $1 \mathrm{~mL}$ of affinity purification lysis buffer (see above) with NP-40 at $0.5 \%$, with or without $1 \mathrm{mg} / \mathrm{mL}$ RNase A (Roche), and cleared by centrifugation, and the background binging was reduced by 1 $\mathrm{h}$ of incubation with protein A/protein G-coupled Sepharose beads (Sigma). After a brief centrifugation, the supernatants were incubated overnight at $4^{\circ} \mathrm{C}$ on a mixing wheel, with 1 $\mu \mathrm{g} / \mathrm{mL}$ anti-eIF3 $\beta$, goat polyclonal antibody E-15 (Santa Cruz Biotechnology), or with an irrelevant antibody (goat polyclonal anti-Hes-6). Antibody-bound eIF3 $\beta$ and its partners were collected on protein A/protein G-coupled Sepharose beads, washed five times with lysis buffer, and subjected to SDS-PAGE and Western blot analysis. Quantification was carried out using Bio Profil software.

\section{Northern blot detection of miR-125b}

Total RNA was prepared using the RNAgents total RNA Isolation System. For Northern blot analyses, $30 \mu \mathrm{g}$ of total RNA were separated on $15 \%$ denaturing ( $7 \mathrm{M}$ urea) polyacrylamide gels (Invitrogen) and electro-transferred to Hybond- $\mathrm{N}^{+}$membranes (Amersham Biosciences). A DNA antisense probe complementary to the mature form of miR-125b was end-labeled with T4 polynucleotide kinase (BioLabs), using $\left[\gamma^{-32} \mathrm{P}\right] \mathrm{ATP}$ with high specific 
activity (6000 Ci/mmol; Amersham). Hybridization was carried out in Rapid-hyb buffer (Amersham). The membranes were washed in the following buffers: $2 \times$ SSC/0.2\% SDS, $1 \times$ SSC/ $0.2 \%$ SDS, and $0.1 \times$ SSC $/ 0.2 \%$ SDS, $15 \mathrm{~min}$ in each buffer. Both hybridization and washing were carried out at $42^{\circ} \mathrm{C}$. Small nuclear RNA U6 was used as loading control.

Sucrose gradients, $q R T-P C R$, and Northern blot detection of IGF-2 transcripts

Total lysate from C2C12 myoblasts or from PMs $\left(3 \times 10^{7}\right.$ cells $)$ was prepared as described in Nielsen et al. (1999), treated or not with $10 \mathrm{mM}$ puromycin or $1 \mathrm{mg} / \mathrm{mL}$ RNase A for $15 \mathrm{~min}$ at $37^{\circ} \mathrm{C}$, and applied to a $21 \%-47 \%$ sucrose gradient in $20 \mathrm{mM}$ Tris- $\mathrm{HCl}(\mathrm{pH} 8.0), 140 \mathrm{mM} \mathrm{KCl}$, and $5 \mathrm{mM} \mathrm{MgCl}_{2}$. Centrifugation was carried out at 40,000 rpm for $2 \mathrm{~h} 15$ min using a Beckman SW41 rotor. One-milliliter fractions were collected, adsorbance at $260 \mathrm{~nm}$ was measured, half of each fraction was precipitated by $10 \%$ trichloroacetic acid, and the proteins were analyzed by Western blot. The second half of each fraction was ethanol-precipitated and treated with DNase (Promega), and RNA was extracted with phenol-chloroform and used for qRTPCR analysis.

The qRT-PCR primer sequences were as follows: IGF-2 coding region, 5'-GTGCTGCATCGCTGCTTACG-3' and 5'GGAAGTACGGCCTGAGAGGT-3'; IGF-2 Leader 3, 5'-AT TACACGCTTTCTGTTTCTCTCC- ${ }^{\prime}$ and $5^{\prime}$-AAATGAGGT CAGCTGTTGTATCAAG-3'; 36B4, 5'-ATGTGCAGCTGAT AAAGACTG-3' and 5'-AGGCCTTGACCTTTTCAGTAA-3'.

For Northern blot analysis, total RNA from the sucrose gradient fractions was separated on a $1.2 \%$ MOPS-agarose gel, transferred to a nylon membrane by capillary transfer, and hybridized according to standard protocols. A $\left[{ }^{32} \mathrm{P}\right]$-labeled probe corresponding to the 246-bp sequence of the $5^{\prime}$ part of the mouse IGF- 2 coding region was generated by PCR using the qRT-PCR IGF-2 primers (see above).

\section{In vitro translation assay}

His-tagged Lin-28 or an irrelevant His-tagged protein of equal size and equal number of methionines (CBP amino acids 21892393) was expressed in the TnT Coupled Reticulocyte Lysate Systems (Promega), using $\left[{ }^{35} \mathrm{~S}\right]$-methionine labeling, and purified using the MagZ Protein Purification System (Promega), according to the manufacturers' instructions. Normalization of recombinant proteins separated on SDS-PAGE was carried out by exposure to the PhosphorImager screen followed by Image Quant quantification. Increasing amounts of recombinant Lin28 or control protein were added to TnT Coupled Reticulocyte Lysate reactions containing $0.1 \mu \mathrm{g}$ of IGF-2 luciferase reporter or a control vector. The IGF-2 luciferase reporter used in this experiment is based on pcDNA 3.1, and contains a Leader 3 regulatory element from the human IGF-2 transcript (1164 bp), inserted into a HindIII site, between a T7 promoter and the firefly luciferase gene inserted into EcoRI-Xba I sites (obtained from Dr. J. Christiansen). To obtain a control construct, we excised the HindIII IGF-2 regulatory sequence, and religated the vector. The effect of on IGF-2 Leader 3 sequence was evaluated by luciferase production.

\section{Antibodies}

Western blot: Lin-28, rabbit antibody was kindly provided by Dr. A. Dutta; MCK, rabbit antibody was kindly provided by Dr. H. Ito; $\alpha$-tubulin, clone DM1A (Sigma); IMP 1-3, rabbit antibodies were kindly provided by Professor F.C. Nielsen; eIF3 $\beta$, goat polyclonal E-15 (Santa Cruz Biotechnology); nucleolin, rabbit polyclonal N2662 (Sigma); IGF-2, clone S1F2 (Upstate Biotechnology).

Immunofluorescence: MHC, mouse monoclonal MY-32 (Sigma); Lin-28, rat antibody was obtained from Dr. E.G. Moss; eIF3 $\beta$, see above; TIA-1, goat IgG C-20 (Santa Cruz Biotechnology); nucleolin, see above.

IGF-2 neutralizing and immunoprecipitating antibodies: mouse monoclonal IgG1 S1F2 (Upstate Biotechnology) and goat IgG AF792 (R\&D Systems). Irrelevant control: mixture of isotype-matched mouse monoclonal F5D anti-myogenin (Developmental Studies Hybridoma Bank) and goat IgG D-20 anti-Hes-6 (Santa Cruz Biotechnology).

\section{Acknowledgments}

The authors thank Drs. J. Christiansen, F.C. Nielsen, A. Dutta, V. Ogryzko, P. Bouvet, A. Hamiche, and S. Leibovich for kind gifts of reagents and cells; Drs. M. Buckingham, F. Relaix, and D. Montarras for the Pax3-GFP mice; K. Kemper for the Lin-28GFP construct; L. Pelletier for obtaining the Lin-28 mutants; Dr. L. Pritchard for critical reading of the manuscript; and Drs. D. Weil and R. Groisman for many helpful discussions. This work was supported by a grant to A.P. from the AFM (1'Association Française contre les Myopathies).

\section{References}

Adachi, S., Ito, H., Akimoto, H., Tanaka, M., Fujisaki, H., Marumo, F., and Hiroe, M. 1994. Insulin-like growth factor-II induces hypertrophy with increased expression of muscle specific genes in cultured rat cardiomyocytes. J. Mol. Cell. Cardiol. 26: 789-795.

Anderson, P. and Kedersha, N. 2002. Visibly stressed: The role of eIF2, TIA-1, and stress granules in protein translation. Cell Stress Chaperones 7: 213-221.

Armand, A.S., Lecolle, S., Launay, T., Pariset, C., Fiore, F., Della Gaspera, B., Birnbaum, D., Chanoine, C., and Charbonnier, F. 2004. IGF-II is up-regulated and myofibres are hypertrophied in regenerating soleus of mice lacking FGF6. Exp. Cell Res. 297: 27-38.

Bagga, S., Bracht, J., Hunter, S., Massirer, K., Holtz, J., Eachus, R., and Pasquinelli, A.E. 2005. Regulation by let-7 and lin-4 miRNAs results in target mRNA degradation. Cell 122: 553 563.

Battler, A., Hasdai, D., Goldberg, I., Ohad, D., Di Segni, E., Bor, A., Varda-Bloom, N., Vered, Z., Kornowski, R., Lake, M., et al. 1995. Exogenous insulin-like growth factor II enhances post-infarction regional myocardial function in swine. Eur. Heart J. 16: 1851-1859.

Boehm, M. and Slack, F. 2005. A developmental timing microRNA and its target regulate life span in C. elegans. Science 310: 1954-1957.

DeVol, D.L., Rotwein, P., Sadow, J.L., Novakofski, J., and Bechtel, P.J. 1990. Activation of insulin-like growth factor gene expression during work-induced skeletal muscle growth. Am. J. Physiol. 259: E89-E95.

Duquet, A., Polesskaya, A., Cuvellier, S., Ait-Si-Ali, S., Hery, P., Pritchard, L.L., Gerard, M., and Harel-Bellan, A. 2006. Acetylation is important for MyoD function in adult mice. $E M B O$ Rep. 7: 1140-1146.

Florini, J.R., Magri, K.A., Ewton, D.Z., James, P.L., Grindstaff, K., and Rotwein, P.S. 1991. 'Spontaneous' differentiation of skeletal myoblasts is dependent upon autocrine secretion 
of insulin-like growth factor-II. J. Biol. Chem. 266: 1591715923.

Florini, J.R., Ewton, D.Z., and Coolican, S.A. 1996. Growth hormone and the insulin-like growth factor system in myogenesis. Endocr. Rev. 17: 481-517.

Guo, Y., Chen, Y., Ito, H., Watanabe, A., Ge, X., Kodama, T., and Aburatani, H. 2006. Identification and characterization of lin-28 homolog B (LIN28B) in human hepatocellular carcinoma. Gene 384: 51-61.

Hansen, T.V., Hammer, N.A., Nielsen, J., Madsen, M., Dalbaeck, C., Wewer, U.M., Christiansen, J., and Nielsen, F.C. 2004. Dwarfism and impaired gut development in insulinlike growth factor II mRNA-binding protein 1-deficient mice. Mol. Cell. Biol. 24: 4448-4464.

Hristova, M., Birse, D., Hong, Y., and Ambros, V. 2005. The Caenorhabditis elegans heterochronic regulator LIN-14 is a novel transcription factor that controls the developmental timing of transcription from the insulin/insulin-like growth factor gene ins-33 by direct DNA binding. Mol. Cell. Biol. 25: 11059-11072.

Huang, C.Y., Hao, L.Y., and Buetow, D.E. 2002. Insulin-like growth factor-II induces hypertrophy of adult cardiomyocytes via two alternative pathways. Cell Biol. Int. 26: 737739.

Husmann, I., Soulet, L., Gautron, J., Martelly, I., and Barritault, D. 1996. Growth factors in skeletal muscle regeneration. Cytokine Growth Factor Rev. 7: 249-258.

Ivanov, P.A., Chudinova, E.M., and Nadezhdina, E.S. 2003. Disruption of microtubules inhibits cytoplasmic ribonucleoprotein stress granule formation. Exp. Cell Res. 290: 227-233.

Kedersha, N. and Anderson, P. 2002. Stress granules: Sites of mRNA triage that regulate mRNA stability and translatability. Biochem. Soc. Trans. 30: 963-969.

Kedersha, N., Stoecklin, G., Ayodele, M., Yacono, P., LykkeAndersen, J., Fitzler, M.J., Scheuner, D., Kaufman, R.J., Golan, D.E., and Anderson, P. 2005. Stress granules and processing bodies are dynamically linked sites of mRNP remodeling. J. Cell Biol. 169: 871-884.

Lee, Y.S., Kim, H.K., Chung, S., Kim, K.S., and Dutta, A. 2005. Depletion of human micro-RNA miR-125b reveals that it is critical for the proliferation of differentiated cells but not for the down-regulation of putative targets during differentiation. J. Biol. Chem. 280: 16635-16641.

Minniti, C.P. and Helman, L.J. 1993. IGF-II in the pathogenesis of rhabdomyosarcoma: A prototype of IGFs involvement in human tumorigenesis. Adv. Exp. Med. Biol. 343: 327-343.

Montarras, D., Morgan, J., Collins, C., Relaix, F., Zaffran, S., Cumano, A., Partridge, T., and Buckingham, M. 2005. Direct isolation of satellite cells for skeletal muscle regeneration. Science 309: 2064-2067.

Morgan, J.E. and Partridge, T.A. 2003. Muscle satellite cells. Int. J. Biochem. Cell Biol. 35: 1151-1156.

Moss, E.G. and Tang, L. 2003. Conservation of the heterochronic regulator Lin-28, its developmental expression and microRNA complementary sites. Dev. Biol. 258: 432-442.

Moss, E.G., Lee, R.C., and Ambros, V. 1997. The cold shock domain protein LIN-28 controls developmental timing in $C$. elegans and is regulated by the lin-4 RNA. Cell 88: 637-646.

Nakatani, Y. and Ogryzko, V. 2003. Immunoaffinity purification of mammalian protein complexes. Methods Enzymol. 370: 430-444.

Nielsen, J., Christiansen, J., Lykke-Andersen, J., Johnsen, A.H., Wewer, U.M., and Nielsen, F.C. 1999. A family of insulinlike growth factor II mRNA-binding proteins represses translation in late development. Mol. Cell. Biol. 19: 1262-1270.

Panar, L.C. and Nair, K.K. 1975. Cytochemistry of the differen- tiating flight muscles of the desert locust Schistocerca gregaria. Histochemistry 45: 129-141.

Piccioni, F., Zappavigna, V., and Verrotti, A.C. 2005. Translational regulation during oogenesis and early development: The cap-poly(A) tail relationship. C.R. Biol. 328: 863-881.

Polesskaya, A., Seale, P., and Rudnicki, M.A. 2003. Wnt signaling induces the myogenic specification of resident CD $45^{+}$ adult stem cells during muscle regeneration. Cell 113: 841852.

Richards, M., Tan, S.P., Tan, J.H., Chan, W.K., and Bongso, A. 2004. The transcriptome profile of human embryonic stem cells as defined by SAGE. Stem Cells 22: 51-64.

Rotwein, P. and Hall, L.J. 1990. Evolution of insulin-like growth factor II: Characterization of the mouse IGF-II gene and identification of two pseudo-exons. DNA Cell Biol. 9: 725-735.

Seggerson, K., Tang, L., and Moss, E.G. 2002. Two genetic circuits repress the Caenorhabditis elegans heterochronic gene lin-28 after translation initiation. Dev. Biol. 243: 215-225.

Sempere, L.F., Freemantle, S., Pitha-Rowe, I., Moss, E., Dmitrovsky, E., and Ambros, V. 2004. Expression profiling of mammalian microRNAs uncovers a subset of brain-expressed microRNAs with possible roles in murine and human neuronal differentiation. Genome Biol. 5: R13.

Teerink, H., Kasperaitis, M.A., De Moor, C.H., Voorma, H.O., and Thomas, A.A. 1994. Translation initiation on the insulin-like growth factor II leader 1 is developmentally regulated. Biochem. J. 303: 547-553.

Viens, A., Mechold, U., Brouillard, F., Gilbert, C., Leclerc, P., and Ogryzko, V. 2006. Analysis of human histone H2AZ deposition in vivo argues against its direct role in epigenetic templating mechanisms. Mol. Cell. Biol. 26: 5325-5335.

$\mathrm{Wu}, \mathrm{L}$. and Belasco, J.G. 2005. Micro-RNA regulation of the mammalian lin-28 gene during neuronal differentiation of embryonal carcinoma cells. Mol. Cell. Biol. 25: 9198-9208.

Yaffe, D. and Saxel, O. 1977. Serial passaging and differentiation of myogenic cells isolated from dystrophic mouse muscle. Nature 270: 725-727.

Yang, D.H. and Moss, E.G. 2003. Temporally regulated expression of Lin-28 in diverse tissues of the developing mouse. Brain Res. Gene Expr. Patterns 3: 719-726.

Yoshiko, Y., Hirao, K., and Maeda, N. 2002. Differentiation in $\mathrm{C}(2) \mathrm{C}(12)$ myoblasts depends on the expression of endogenous IGFs and not serum depletion. Am. J. Physiol. Cell Physiol. 283: C1278-C1286.

Zammit, P.S., Partridge, T.A., and Yablonka-Reuveni, Z. 2006. The skeletal muscle satellite cell: The stem cell that came in from the cold. J. Histochem. Cytochem. 54: 1177-1191. 


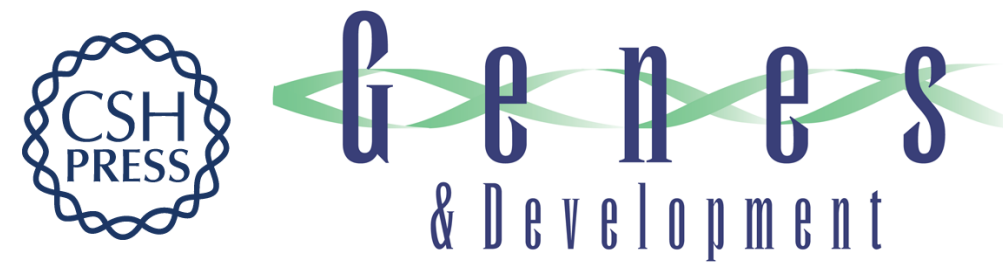

\section{Lin-28 binds IGF-2 mRNA and participates in skeletal myogenesis by increasing translation efficiency}

Anna Polesskaya, Sylvain Cuvellier, Irina Naguibneva, et al.

Genes Dev. 2007, 21:

Access the most recent version at doi:10.1101/gad.415007

\section{Supplemental http://genesdev.cshlp.org/content/suppl/2007/04/16/21.9.1125.DC1 Material}

References This article cites 40 articles, 11 of which can be accessed free at: http://genesdev.cshlp.org/content/21/9/1125.full.html\#ref-list-1

\section{License}

Email Alerting

Receive free email alerts when new articles cite this article - sign up in the box at the top Service

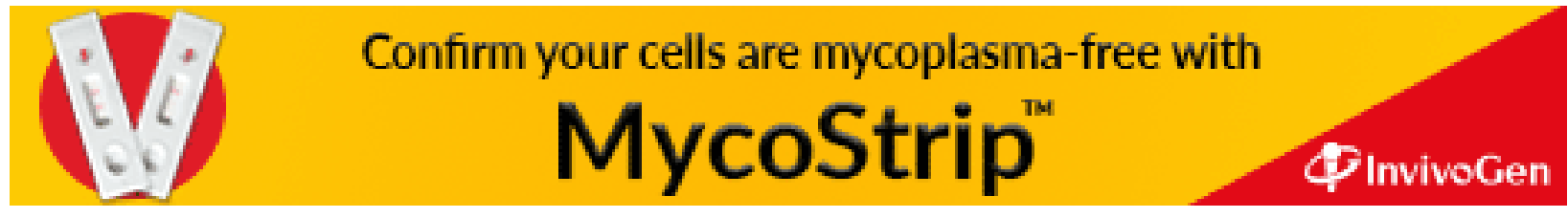

